\title{
Use of a Genesis Potential Index to Diagnose ENSO Effects on Tropical Cyclone Genesis
}

\author{
SuZANa J. CAMARgo \\ International Research Institute for Climate and Society, Lamont Campus, Palisades, New York \\ KERRY A. EMANUEL \\ Program in Atmospheres, Oceans, and Climate, Massachusetts Institute of Technology, Cambridge, Massachusetts \\ ADAM H. SOBEL \\ Department of Applied Physics and Applied Mathematics, and Department of Earth and Environmental Sciences, \\ Columbia University, New York, New York
}

(Manuscript received 20 June 2006, in final form 12 February 2007)

\begin{abstract}
ENSO (El Niño-Southern Oscillation) has a large influence on tropical cyclone activity. The authors examine how different environmental factors contribute to this influence, using a genesis potential index developed by Emanuel and Nolan. Four factors contribute to the genesis potential index: low-level vorticity $(850 \mathrm{hPa})$, relative humidity at $600 \mathrm{hPa}$, the magnitude of vertical wind shear from 850 to $200 \mathrm{hPa}$, and potential intensity (PI). Using monthly NCEP Reanalysis data in the period of 1950-2005, the genesis potential index is calculated on a latitude strip from $60^{\circ} \mathrm{S}$ to $60^{\circ} \mathrm{N}$. Composite anomalies of the genesis potential index are produced for El Niño and La Niña years separately. These composites qualitatively replicate the observed interannual variations of the observed frequency and location of genesis in several different basins. This justifies producing composites of modified indices in which only one of the contributing factors varies, with the others set to climatology, to determine which among the factors are most important in causing interannual variations in genesis frequency. Specific factors that have more influence than others in different regions can be identified. For example, in El Niño years, relative humidity and vertical shear are important for the reduction in genesis seen in the Atlantic basin, and relative humidity and vorticity are important for the eastward shift in the mean genesis location in the western North Pacific.
\end{abstract}

\section{Introduction}

Understanding the influence of large-scale environmental factors on tropical cyclogenesis is a problem of great scientific and societal importance. While much is known about which factors influence genesis, a quantitative theory is lacking. In the absence of such a theory, empirical methods are useful. Gray (1979) developed an index that was able to replicate key features of the seasonal and spatial variability of observed genesis using a handful of environmental parameters. Such an index is useful in several ways. First, it provides an empirical quantification of the relative contributions of

Corresponding author address: Suzana Camargo, IRI-225 Monell Bldg., P.O. Box 1000, Palisades, NY 10964-8000.

E-mail: suzana@iri.columbia.edu various environmental factors toward genesis. Second, it may conceivably be useful in developing schemes for forecasting tropical cyclone (TC) number, to the extent that an independent capability exists to forecast the large-scale environmental variables which enter the index.

Here, we present another genesis index and construct composites of it with respect to both the annual cycle and the El Niño-Southern Oscillation (ENSO) phenomenon. Our first goal is to evaluate the ability to represent observed variations of tropical cyclone number with the annual cycle and ENSO in various basins. These are fair tests of the index since the index was constructed with only climatological information for each hemisphere as a whole. The test of the ability of the index to reproduce observed ENSO signals is perhaps the first one the index must pass in order to be

DOI: $10.1175 /$ JCLI4282.1 
useful for forecasting, since ENSO is the largest single predictable factor influencing genesis in some basins. Our second goal is to use the index to determine which specific environmental factors are most influential in determining ENSO-related variations in genesis in the various basins. The index weights the various factors (sea surface temperature, wind shear, etc.) with specific functional dependences, which empirically have been found to be appropriate to represent their relative importance in the climatology (and, in this study, also to their variability with ENSO). Modified indices were constructed in which all but one factor is set to the climatology, while the interannual variability is retained in the remaining factor. ENSO composites were then constructed for these modified indices in order to asses the role of each particular factor in ENSO variability. By repeating this procedure for each factor separately and comparing the results, we provide a quantitative basis for stating that one factor is more important than another in inducing the ENSO signal in a given region.

\section{Development of the genesis potential index}

The genesis potential (GP) index developed by Emanuel and Nolan (2004) was motivated by the work of Gray (1979). Here we describe the development of the index in more detail.

We began with a large set of environmental variables that, on physical grounds, we believed might be important predictors. In selecting combinations of such variables, we avoided the use of parameters that might be specific to the present climate. For example, we did not use a specific threshold for SST (sea surface temperature), as in Gray's index, as we wanted an index that would be valid in different climate scenarios. There are no grounds for believing that $26^{\circ} \mathrm{C}$ is a constant of nature. Royer et al. (1998) show that the use of this SST threshold limits the validity of Gray's index under climate change.

The initial set of predictors included the potential intensity (PI; Emanuel 1988), relative humidity, absolute vorticity at various levels, and wind shear. The wind shear is defined as the magnitude of the vector difference between the horizontal winds at 850 and 200 $\mathrm{hPa}$, as is often used in empirical studies of tropical cyclone genesis and intensity change. While in principle it would be desirable to include as predictors wind shears defined between different levels, the classical definition was retained primarily because satellite cloud-track winds are most abundant in the lower troposphere, where trade cumulus develop, and near the tropical tropopause, where cirrus clouds are often found.
The predictors were evaluated using the National Centers for Environmental Prediction (NCEP) Reanalysis data (Kalnay et al. 1996) from 1950 to 2004. The potential intensity $V_{\text {pot }}$ is obtained from sea surface temperature, sea level pressure, and vertical profiles of atmospheric temperature and humidity using a technique that is a generalization of that described in Emanuel (1995) to take into account dissipative heating, as discussed in Bister and Emanuel (1998). Technical details of the calculation of potential intensity may be found in Bister and Emanuel (2002a,b), who also presented some estimates of its climatological, lowfrequency variability. A short definition of the potential intensity can be found in the appendix.

Genesis locations and times were taken from socalled "best track" datasets maintained for the Atlantic and eastern North Pacific by the NOAA National Hurricane Center, and for the rest of the world oceans by the U.S. Navy's Joint Typhoon Warning Center. Only post-1970 data were used. Monthly average values of each of the predictors were then tested individually and in combination for their ability to replicate the annual cycle of tropical cyclogenesis rates in each hemisphere, as well as for their ability to replicate the spatial distribution of genesis in each month of the year. This process was partly objective, using standard multiple regression techniques, but also partly subjective, in the selection of combinations of variables and the choice of which variables to retain. We make no claim that the resulting index represents a globally optimum combination of the chosen predictors.

The index, as presented by Emanuel and Nolan (2004), is defined as

$$
\mathrm{GP}=\left|10^{5} \eta\right|^{3 / 2}\left(\frac{\mathcal{H}}{50}\right)^{3}\left(\frac{V_{\text {pot }}}{70}\right)^{3}\left(1+0.1 V_{\text {shear }}\right)^{-2},
$$

where $\eta$ is the absolute vorticity at $850 \mathrm{hPa}$ (in s ${ }^{-1}$ ), $\mathcal{H}$ is the relative humidity at $600 \mathrm{hPa}$ in percent, $V_{\text {pot }}$ is the potential intensity (in $\mathrm{m} \mathrm{s}^{-1}$ ), and $V_{\text {shear }}$ is the magnitude of the vertical wind shear between $850 \mathrm{hPa}$ and $200 \mathrm{hPa}\left(\right.$ in $\mathrm{m} \mathrm{s}^{-1}$ ). Aside from the coefficient multiplying the shear, the constants that appear in this definition are entirely arbitrary and simply designed to give an index value of order unity. Although the index should be interpreted as a rate per unit time per unit area, a constant multiplier would have to be included in the index to give it the appropriate magnitude and dimensions. In developing the index, its log was fit to the best track data using multiple regression, but experimenting empirically with the shear factor to optimize its fit to the data. The exponents that appear in the index have been rounded to the nearest half integer as the fit to the data does not warrant more precision. 
(a)

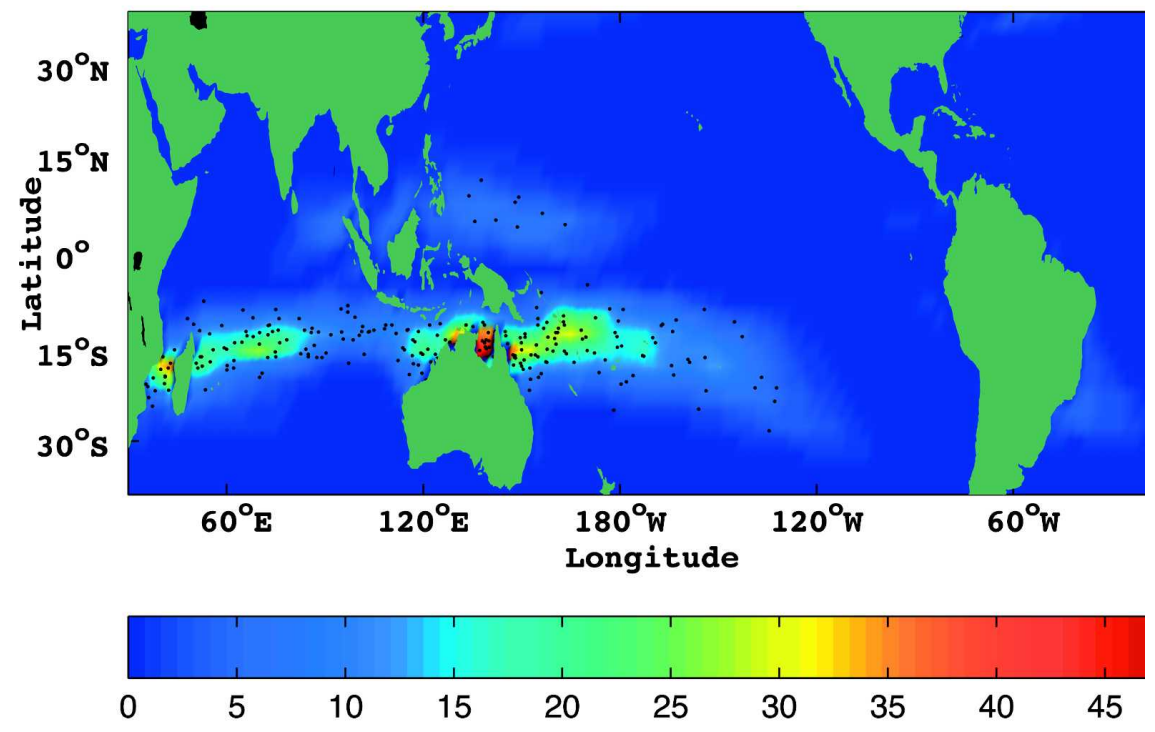

(b)
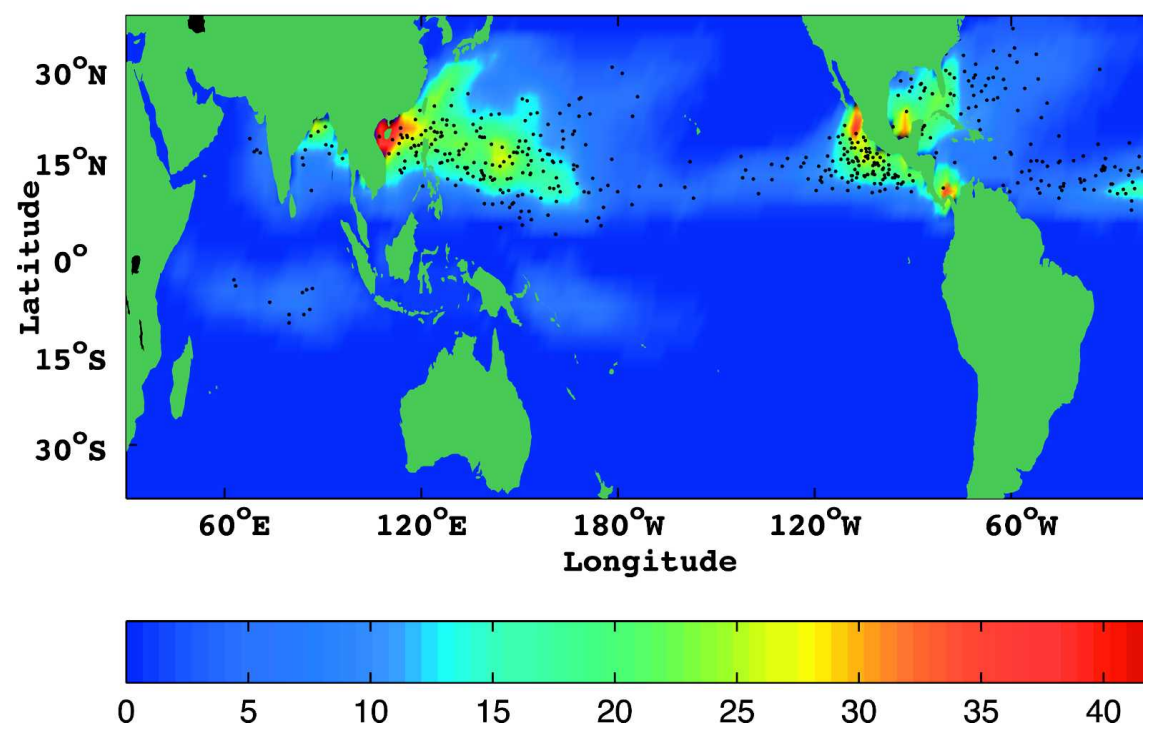

FIG. 1. Genesis potential index climatology in (a) February and (b) September. The black dots show individual genesis events over the period from (a) 1970 to 2004 and (b) 1970 to 2005.

The seasonal genesis index developed by Gray (1979; Watterson et al. 1995) has some similarities with GP, but also some important differences. A few of the variables are common to both indices, such as the vertical wind shear (though using different pressure levels) and the midtropospheric relative humidity. Other variables are somewhat equivalent; for example, while here the absolute low-level vorticity is one of the factors, in Gray's index the Coriolis parameter and the relative vorticity are separate variables. The main difference between these indices is in the thermodynamic variable. Here GP uses the potential intensity, which depends on the air-sea thermodynamic disequilibrium and the difference between the sea surface temperature and the temperature at the level of neutral buoyancy for an adiabatically lifted boundary layer parcel. In contrast, Gray's index uses the near-surface ocean thermal energy with a specific threshold $\left(26^{\circ} \mathrm{C}\right)$ and the vertical gradient of the equivalent potential temperature between the surface and $500 \mathrm{hPa}$. 


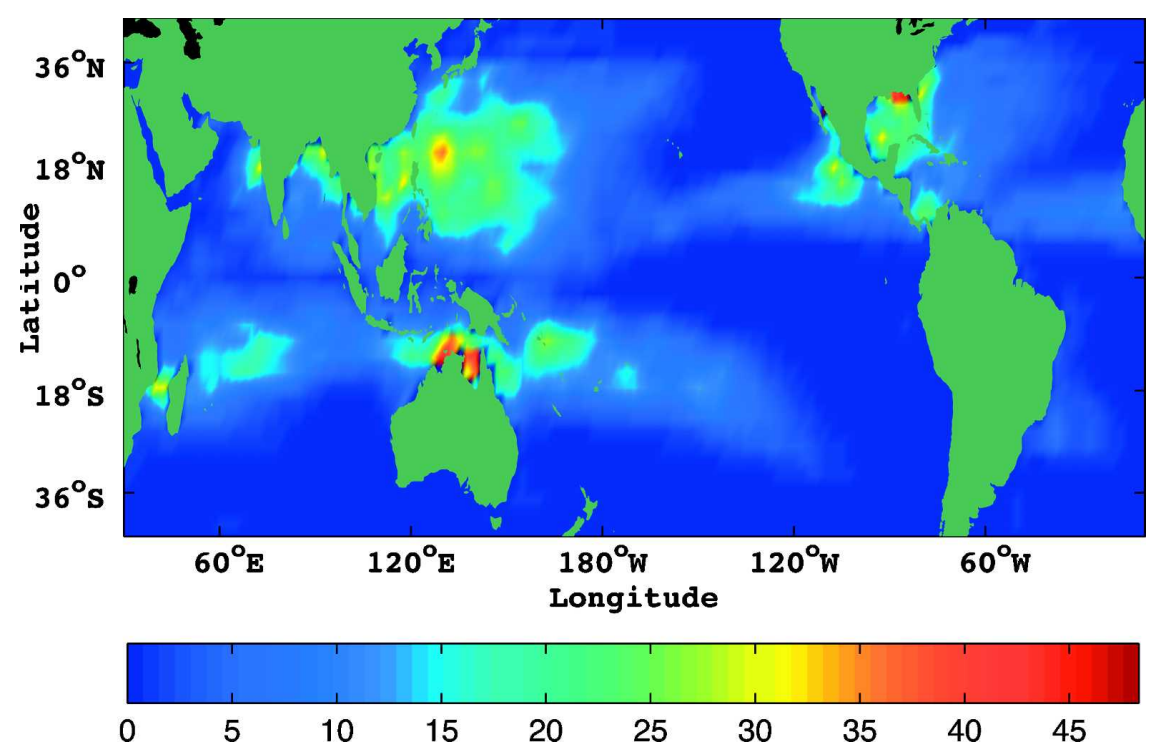

FIG. 2. Maximum value per year of the genesis potential index climatology at each grid point.

Besides the difference in variables used, the indices also differ in the powers and constants used in their definitions. Gray's index is able to reproduce approximately the regions of tropical cyclogenesis in the seasons and basins of tropical cyclone activity (see, e.g., Watterson et al. 1995). An alternative modification of the Gray's index to suppress the dependence on the SST threshold using a convective parameter is discussed in Royer et al. (1998). These genesis indices have also been applied to output from climate models (Ryan et al. 1992; McDonald et al. 2005; Chauvin et al. 2006).

In the following section, we compare the spatial and seasonal distributions of genesis events to those predicted by the GP.

\section{Climatology of the genesis potential index}

Figure 1 shows the climatological values of the genesis potential in February and September, within the peak of the tropical cyclone season in the Southern and Northern Hemisphere, respectively. In Fig. 2 the annual maximum of the genesis potential climatology at each grid point is shown, with all well-known tropicalcyclone-prone regions appearing as maxima of the genesis potential index. While the spatial patterns agree well in a qualitative sense, the spatial distributions of genesis potential and genesis itself do not correspond with great quantitative precision.

The annual cycles of genesis events in each hemisphere are shown in Fig. 3 and compared to the pre- dictions using the genesis potential index. The genesis potential captures the main elements of the seasonal cycle of tropical cyclones.

The index was optimized to give the best fit to the spatial and temporal distributions shown in Figs. 1 and 3. No attempt was made to optimize the index for variability within individual ocean basins, so it is instructive to evaluate the local performance of the index.

The climatology of the genesis potential per basin (for the definitions of the basins used to compute the area averages, see the caption of Table 2), compared with the climatology of the number of tropical cyclones, is shown in Fig. 4 for several basins. The agreement in all basins is very good, with the genesis potential annual cycle's being very similar to that of the number of tropical cyclones. Even in the case of the north Indian Ocean, which has an annual cycle with two peaks, preand postmonsoon, the genesis potential index follows the number of tropical cyclones very closely.

The average number of tropical cyclones observed over each entire basin varies significantly more, from basin to basin, than does the genesis potential. That is, in Fig. 4, there is more variation in the scale on the left than on the right. It seems reasonable to attribute this in large part to the different size of the basins. The western North Pacific, for example, has a much larger area over which conditions are favorable for genesis than do the other basins. This alone should be expected to lead to a larger number of cyclones in the western North Pacific than the other basins-as is observedeven for the same genesis potential per unit area. 
(a)

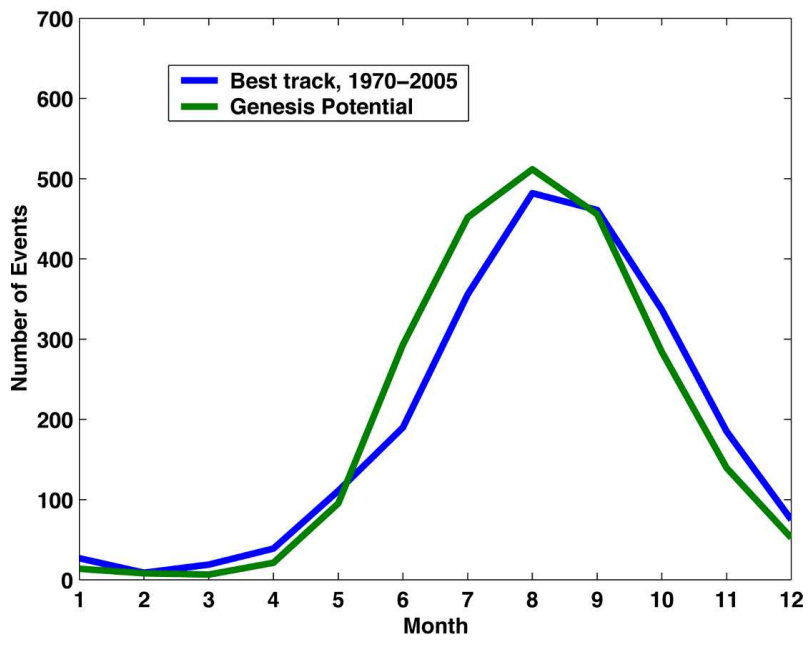

(b)

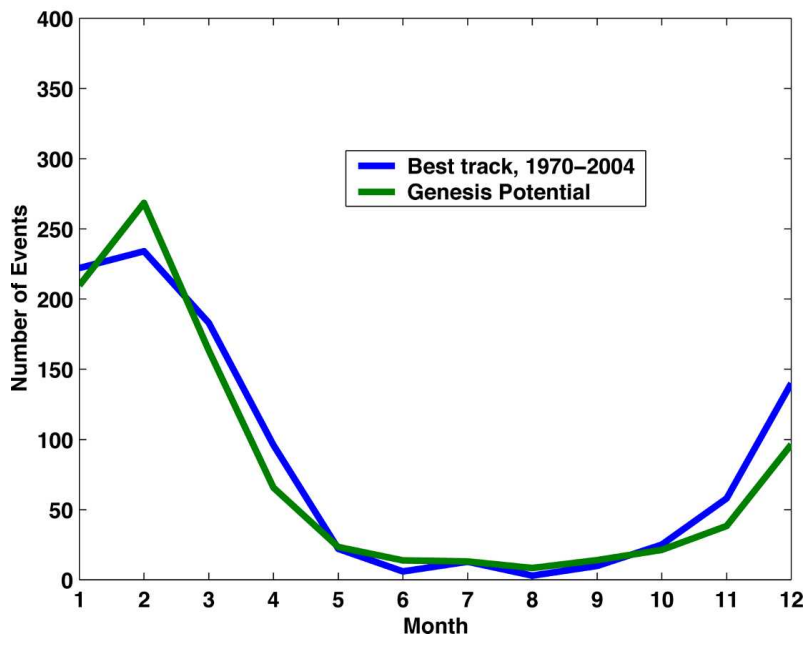

FIG. 3. Genesis potential index climatology and number of genesis events in the (a) Northern and (b) Southern Hemispheres.

The relationship of the genesis potential index to its four constituent variables (potential intensity, vorticity, vertical wind shear, and relative humidity) can be further explored by computing joint probability distribution functions (PDFs) of the index and each of these variables, as shown in Fig. 5. The joint PDFs are estimated from the density of points in the space defined by the index and the other variable, where each point represents the values from an individual grid point in the climatology. All ocean points from $40^{\circ} \mathrm{S}$ to $40^{\circ} \mathrm{N}$ and all seasons are used. These PDFs show that, in the aggregate over all basins, the different variables play somewhat similar roles in determining the climatological distribution of the index. The index has a thresholdlike dependence on potential intensity, wind shear, and relative humidity; there are essentially no large values of the index if shear is large or either relative humidity or potential intensity is small. Very small index values are most often associated with either small potential intensity, small relative humidity, or large shear.

Absolute vorticity does not seem to exhibit threshold behavior at any finite value, though the index does tend to increase with absolute vorticity (as we expect from its construction). The index can also be low when absolute vorticity is high, as in extratropical regions with low potential intensity. The impression one has is that a favorable value of one constituent variable can compensate for an unfavorable value of another to some degree, allowing the index to attain a fairly large value, with the exception that high values of absolute vorticity cannot compensate if the other variables are unfavorable.

Analogous plots using individual basins (not shown) are qualitatively similar, though details differ somewhat from basin to basin, reflecting modest variation in the way the different variables combine to determine the climatological structure of the genesis potential index. We will show below that different variables are important in generating the ENSO signals in the index in different basins.

\section{ENSO and tropical cyclone activity}

The influence of ENSO on tropical cyclone activity in the various basins has been studied by a large number of investigators. Recent reviews of this subject may be found in Landsea (2000) and Chu (2004).

In the Atlantic, in El Niño years, there is a tendency toward fewer tropical cyclones, while the opposite occurs in La Niña years (Gray 1984; Gray and Sheaffer 1991; Gray et al. 1993; Knaff 1997). ENSO also affects the number of landfalls in the United States (Bove et al. 1998; Pielke and Landsea 1999), hurricane intensity (Landsea et al. 1999), and genesis location (Elsner and Kara 1999). Factors that have been identified as responsible for this shift in tropical cyclone activity are vertical wind shear (Shapiro 1987; Goldenberg and Shapiro 1996) and thermodynamic variables (Tang and Neelin 2004).

In the western North Pacific, there is a southeastward (northwestward) shift of tropical cyclone activity in El Niño (La Niña) years (Chan 1985; Dong 1988; Chia and Ropelewski 2002; Wang and Chan 2002). This has been attributed to the eastward extension of the monsoon trough and westerlies in the western North Pacific (Lander 1994, 1996) and reduction of vertical wind shear (Clark and Chu 2002). In El Niño years typhoons 
(a)

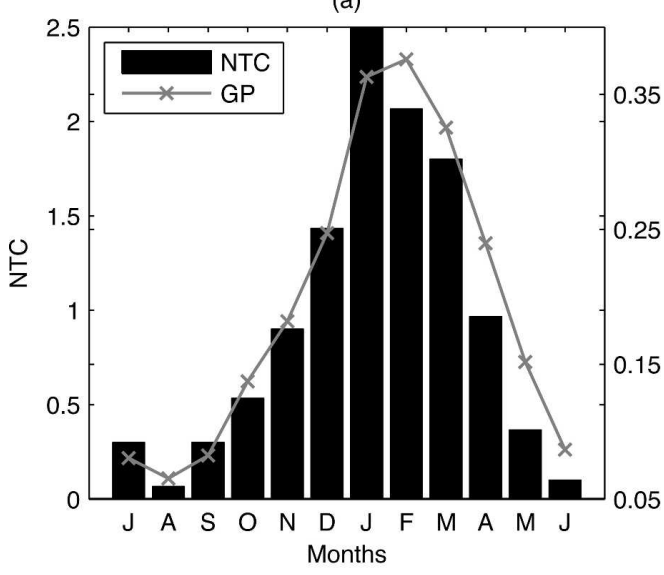

(c)

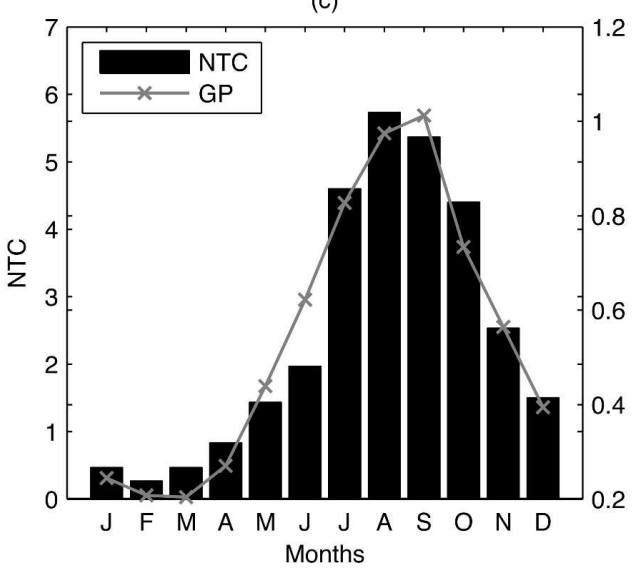

(b)

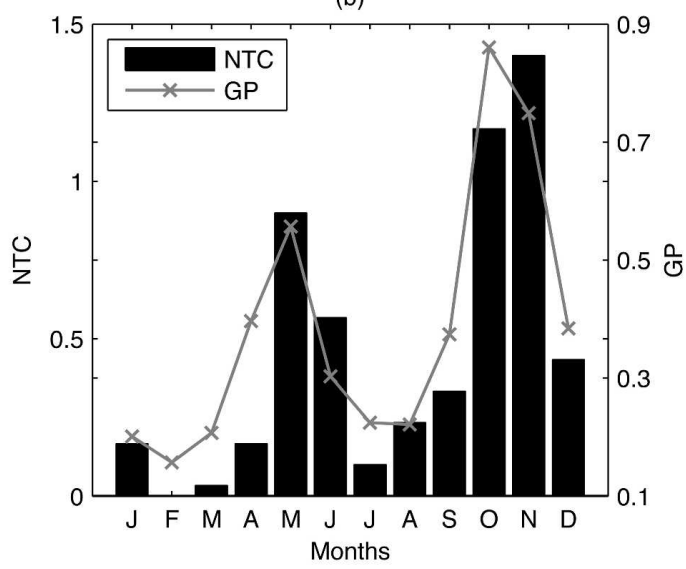

(d)

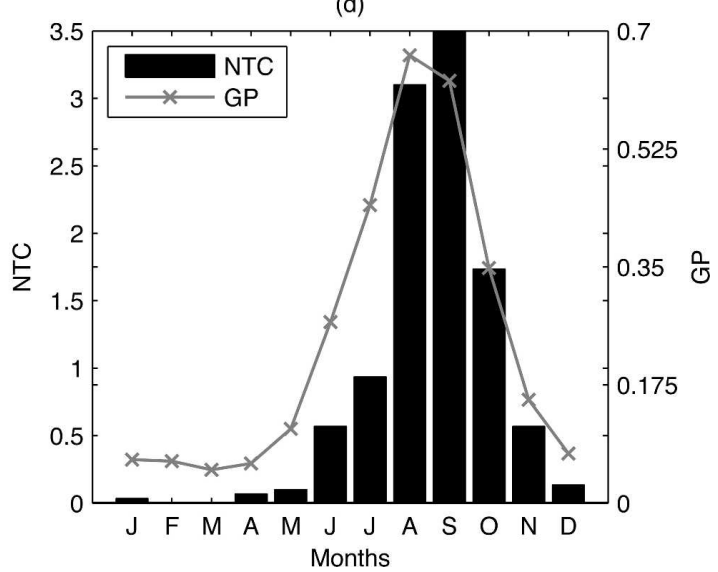

FIG. 4. Genesis potential index and climatological number of tropical cyclones in the (a) South Pacific, (b) north Indian, (c) western North Pacific, and (d) North Atlantic basins.

also tend to last longer, become more intense, and have more recurved trajectories (Wang and Chan 2002; Camargo and Sobel 2005; Camargo et al. 2007), which influences landfall probabilities in Asian countries (Saunders et al. 2000; Elsner and Liu 2003; Wu et al. 2004). Sobel and Camargo (2005) hypothesized that anomalous typhoon-induced near-equatorial westerly winds generated in El Niño years might even act to strengthen the warm event, resulting in a positive feedback between ENSO and tropical cyclones.

More hurricanes tend to form in the central Pacific during El Niño events. More tropical cyclones occur near Hawaii. This has been attributed to smaller vertical wind shear and greater low-level relative vorticity in that region (Wu and Lau 1992; Chu and Wang 1997; Clark and Chu 2002; Chu 2004).

Eastern North Pacific tropical cyclone activity tends to be enhanced when Atlantic tropical cyclone activity is suppressed, and vice versa (Elsner and Kara 1999). Although no ENSO influence has been found in tropi- cal cyclone frequency in the eastern North Pacific (Whitney and Hobgood 1997), the number of intense hurricanes tends to increase in El Niño years (Gray and Sheaffer 1991) and the tropical cyclone activity shifts westward during El Niño events (Irwin and Davis 1999), with an increased likelihood that some of these hurricanes will propagate into the central North Pacific (Chu 2004). This shift has been attributed to environmental parameters having different characteristics east and west of $116^{\circ} \mathrm{W}$ (Collins and Mason 2000) in ENSO years.

There is a strong association between the variabilities of the sea surface temperatures in the Indian and $\mathrm{Pa}$ cific Oceans (Pan and Oort 1983). The association of north Indian Ocean tropical cyclone frequency and ENSO is apparent during the months of May and November, when fewer intense tropical cyclones occur during El Niño events (Singh et al. 2000).

In El Niño years, an increase in the formation of tropical cyclones occurs in the South Pacific near the 
(a)

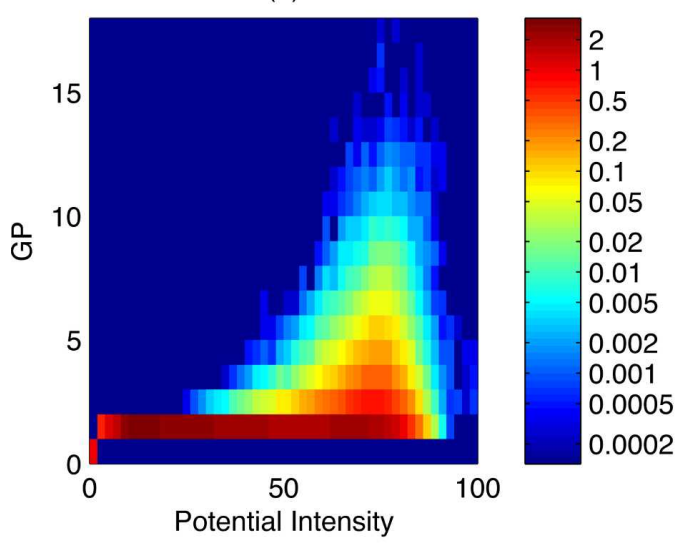

(c)
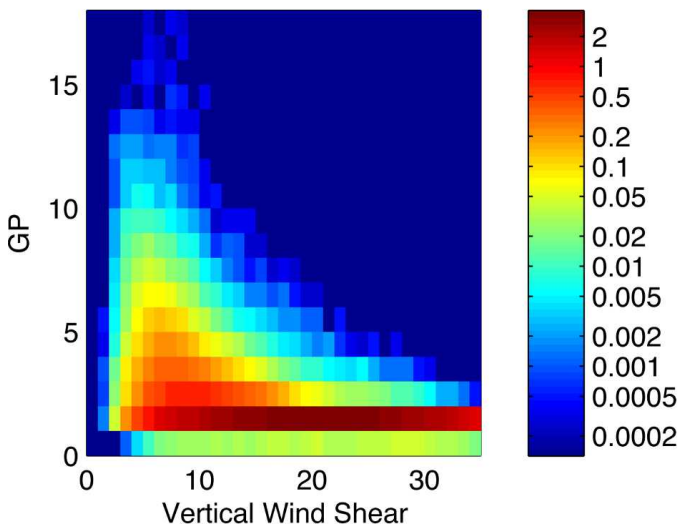

(b)

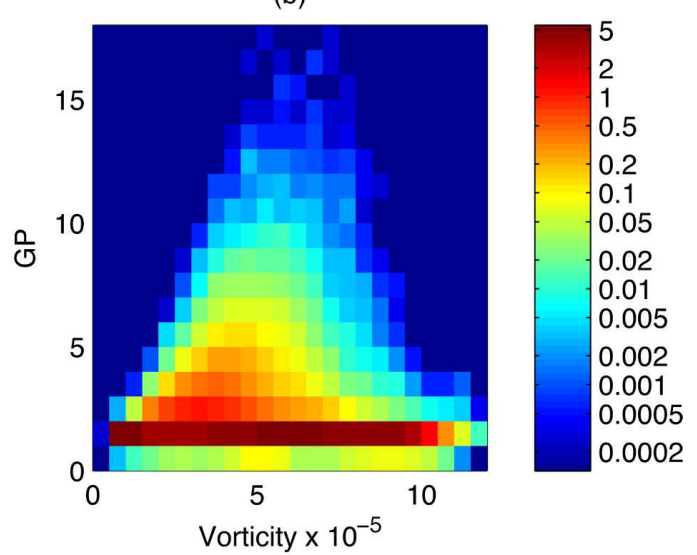

(d)

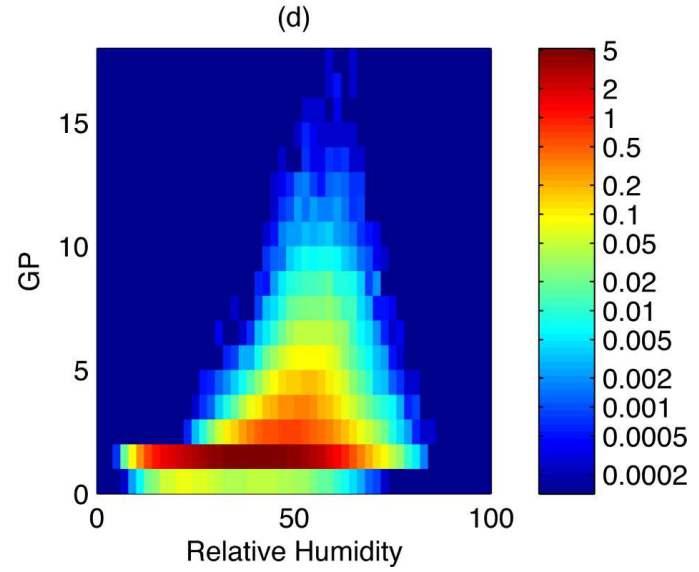

FIG. 5. Joint probability distribution functions of the genesis potential index and (a) potential intensity, (b) vorticity, (c) vertical wind shear, and (d) relative humidity for ocean points in the latitude band $40^{\circ} \mathrm{S}-40^{\circ} \mathrm{N}$.

date line simultaneously with a decrease near Australia (Revell and Goulter 1986; Hastings 1990; Evans and Allan 1992; Basher and Zeng 1995). In La Niña years, an enhanced risk of landfall occurs in Australia with more tropical cyclones tracking close to the Queensland coast, while in El Niño years the tracks are more zonal west of the date line (Nicholls 1979, 1985; Dong 1988; Nicholls et al. 1998). This shift is related to the extension of the monsoon trough and equatorial westerlies in El Niño years in the South Pacific, favoring the formation of twin tropical cyclones (Ferreira et al. 1996), tropical cyclogenesis late in the season and east of $160^{\circ} \mathrm{W}$ in the South Pacific (Chu 2004).

\section{ENSO influence on the genesis potential index}

To assess the environmental factors that determine the ENSO influence on tropical cyclone activity, we begin by calculating the genesis potential index's monthly anomaly (difference from seasonal climatol- ogy) in the period 1950-2005. From these anomalies we obtain seasonal anomaly composites for El Niño and La Niña events. We use the Niño-3.4 index to define El Niño/La Niña events, considering August-October (ASO) values for the Northern Hemisphere and January-March (JFM) values for the Southern Hemisphere. The 13 years (25\% of the cases) with the highest (lowest) Niño-3.4 values in a season are defined as El Niño (La Niña) years with the remaining years defined as neutral years, the same definition used in Goddard and Dilley (2005) and Camargo and Sobel (2005). The ENSO years used in the composites for JFM and ASO are given in Table 1. Figure 6 shows these composites for ASO, the peak period of tropical cyclone activity in the North Atlantic and western North Pacific.

In Fig. 6a the genesis potential anomalies in El Niño years (ASO) show the well-known decrease of cyclone activity in the North Atlantic and western part of the western North Pacific (horseshoe pattern), and an increase in the eastern and central Pacific. An almost 
TABLE 1. El Niño and La Niña years for JFM and ASO used in the composites of the genesis potential index in Figs. 6-11.

\begin{tabular}{lcccc}
\hline \hline \multirow{2}{*}{ JFM } & & & \multicolumn{2}{c}{ ASO } \\
\cline { 5 - 5 } El Niño & La Niña & & El Niño & La Niña \\
\hline 1958 & 1950 & & 1951 & 1950 \\
1966 & 1955 & & 1957 & 1954 \\
1969 & 1956 & & 1963 & 1955 \\
1970 & 1968 & & 1965 & 1956 \\
1973 & 1971 & & 1969 & 1964 \\
1977 & 1974 & & 1972 & 1970 \\
1983 & 1976 & & 1982 & 1971 \\
1987 & 1985 & & 1986 & 1973 \\
1988 & 1986 & & 1987 & 1975 \\
1992 & 1989 & & 1991 & 1988 \\
1995 & 1996 & & 1997 & 1995 \\
1998 & 1999 & 2002 & 1998 \\
2003 & 2000 & 2004 & 1999 \\
\hline
\end{tabular}

mirror image appears in the La Niña years (Fig. 6b), as can be seen especially easily in the difference between El Niño and La Niña years (Fig. 6c).

To provide objective observational metrics with which to compare the genesis index, we compute genesis density and track density from best track data. The genesis density is calculated by counting the number of tropical cyclones with genesis (first position) in each $2.5^{\circ} \times 2.5^{\circ}$ latitude and longitude square. Similarly, for the track density, we count the number of 6-hourly tropical cyclone positions within each $2.5^{\circ} \times 2.5^{\circ}$ latitude and longitude square, normalized such that $24 \mathrm{~h}$ in a particular location for one tropical cyclone is counted as one.

The difference in observed ASO genesis and track density anomalies between El Niño and La Niña years is shown in Fig. 7. In the Northern Hemisphere these differences are clearly similar to those exhibited by the genesis potential index anomalies (cf. Fig. 6c to Fig. 7). The genesis potential index composites in Fig. 6 are able to reproduce the shift in the distribution of Atlantic tropical cyclones between El Niño and La Niña years, for instance. In the next section, we use the genesis potential index to further explore which factors are most responsible for some of these ENSO signals in tropical cyclone activity.

The agreement between observed and predicted El Niño - La Niña differences is not good in the Southern Hemisphere during ASO. There are very few tropical cyclones in the Southern Hemisphere during AugustOctober, so this disagreement is not important.

The JFM genesis potential ENSO anomalies are shown in Fig. 8 [(a) El Niño and (b) La Niña] together with the difference between the El Niño and La Niña anomalies. The El Niño - La Niña differences in genesis density and track density for JFM are shown in Fig. 9. The ENSO-related shifts are more zonal in the Northern Hemisphere (though few tropical cyclones form there in JFM) and more meridional in the Southern Hemisphere. There is also, however, a longitudinal shift in the South Pacific with a positive genesis potential anomaly in El Niño years east of $160^{\circ} \mathrm{E}$ in the South Pacific and a negative anomaly near the Australian continent.

The genesis potential ENSO anomaly differences in ASO and JFM are generally consistent with the known effects of ENSO on tropical cyclones discussed in the previous section, such as the decrease of tropical cyclone activity in the Atlantic in El Niño years accompanied by an increase in the eastern and central Pacific, with a southeastern shift in the western North Pacific.

Table 2 shows the values of the interannual correlations between the genesis potential index and the number of tropical cyclones in the different basins for different seasons. All basins, with the exception of the north Indian Ocean, have significant skill at least in a few seasons. The western North Pacific has significant correlation in the early and late season, but not during the peak of its tropical cyclone activity, when the central North Pacific region has significant skill. This shift in skill is probably related to the spatial shift of tropical cyclone activity in the western North Pacific with ENSO. The Atlantic and the eastern North Pacific have significant correlation in the August-October period, when most of their peak tropical cyclone activity occurs. In the Southern Hemisphere, the south Indian and the South Pacific have significant correlations in November-January (NDJ) and December-February (DJF) seasons.

\section{Factors influencing ENSO effects on the genesis potential index}

Here we assess the individual importance of the four variables that are comprised in the genesis potential (vorticity, vertical wind shear, potential intensity, and humidity) in determining the ENSO anomalies. To do this, we recalculate the genesis potential using the longterm climatology of three of the variables but the unmodified, interannually varying values for the fourth variable. This is then repeated for each of the other three variables. The anomalies and the ENSO composites are then recalculated in all four cases. Owing to the nonlinearity of the GP index, the net anomaly cannot be described as the sum of the four fields described 
(a)

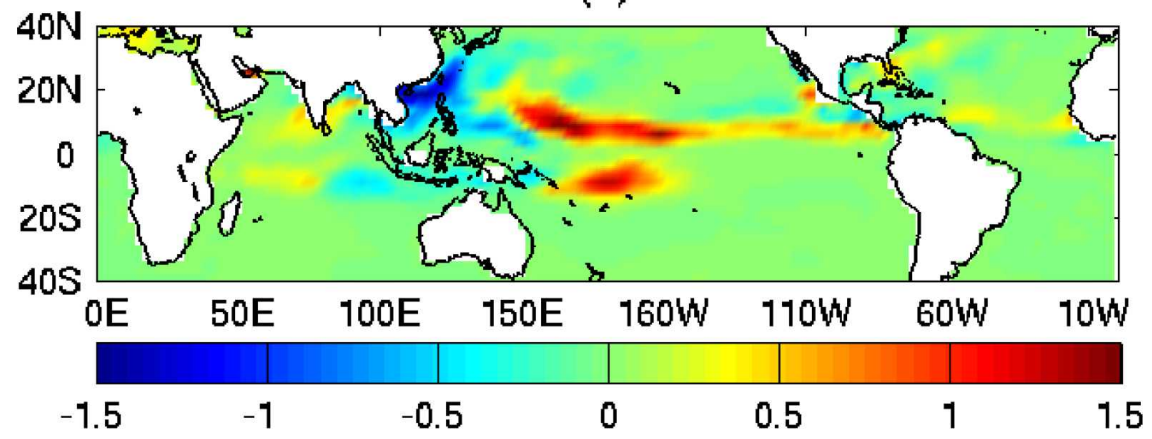

(b)

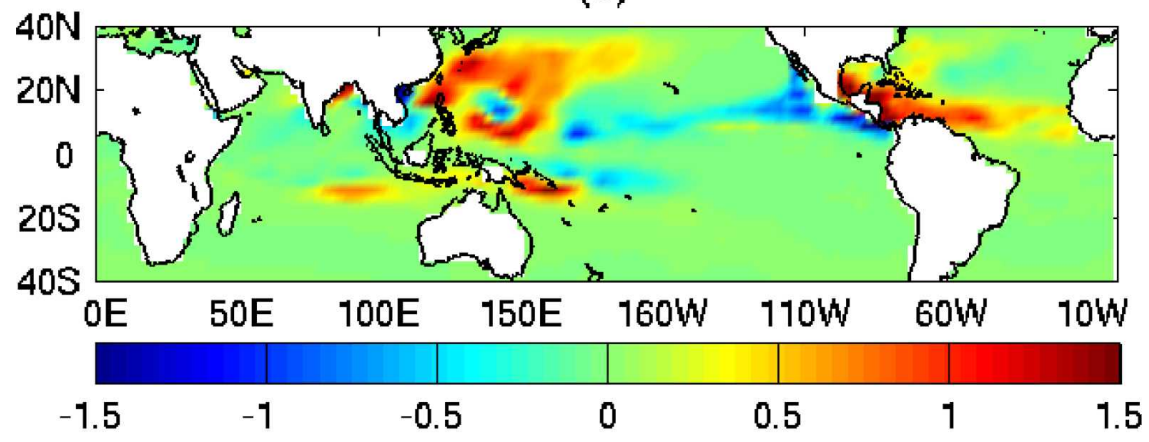

(c)

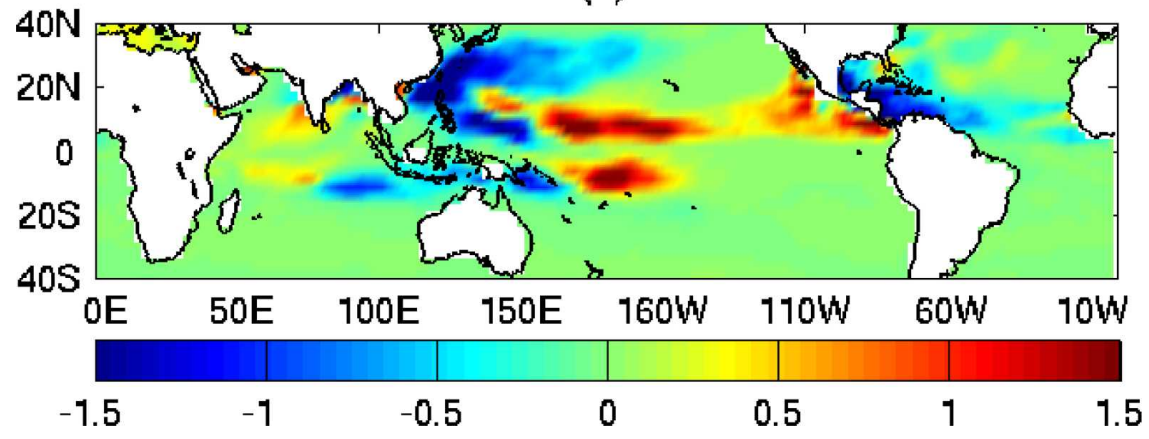

FIG. 6. Genesis potential anomalies in ASO for (a) El Niño and (b) La Niña years; (c) difference of the anomalies in El Niño and La Niña years.

here. Nonetheless, to the extent that the index provides weights that appropriately quantify the roles of the different factors in genesis and the nonlinearities are not too large, the attributions obtained by this method should be meaningful.

Figure 10 shows the El Niño - La Niña difference in genesis potential anomalies for the Southern Hemisphere in JFM, in the cases of varying (a) vorticity (Fig. 10a), (b) vertical wind shear (Fig. 10b), (c) potential intensity (Fig. 10c), and (d) relative humidity (Fig. 10d), in each case with the other three variables fixed at their long-term climatological values. Comparing this with the pattern obtained when all four factors are varying
(Fig. 8c), it is apparent that different factors contribute to the genesis potential anomaly shifts in different regions. The increase in the genesis potential anomalies around $10^{\circ} \mathrm{S}$ is mainly owing to vertical wind shear and vorticity (South Pacific) or vertical wind shear and PI (south Indian). The decrease of the genesis potential anomalies in the south Indian Ocean around $15^{\circ} \mathrm{S}$ and in the Mozambique Channel is mainly owing to vertical wind shear and relative humidity changes. In the South Pacific, from the eastern Australian coast to the east of the date line, the main contribution to the negative genesis potential anomaly is the relative humidity, while east of the date line vertical wind shear and po- 
(a)

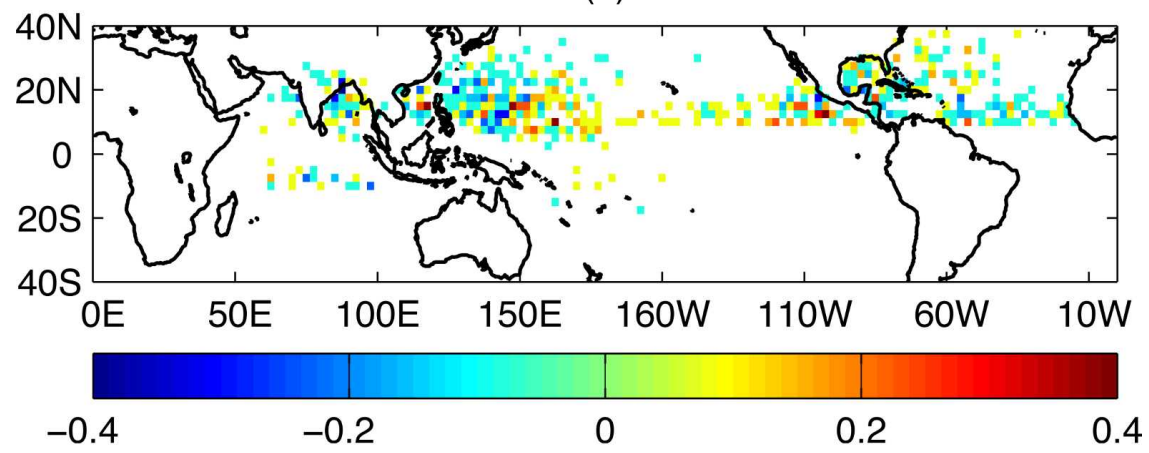

(b)

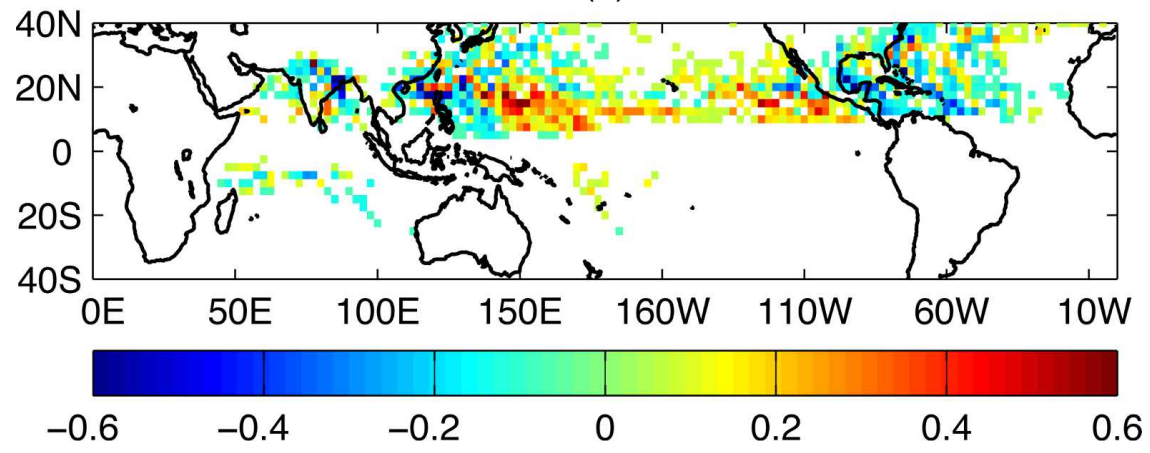

FIG. 7. Difference between anomalies in El Niño and La Niña years of the (a) genesis density and (b) track density in ASO.

tential intensity dominate the differences. Pattern correlations of the genesis potential anomaly with all factors varying and the genesis potential anomaly with only one factor varying confirm these findings (not shown). For instance, in ASO, the pattern correlations of the GP and the GP with varying vertical wind shear are highly significant in the Atlantic.

Figure 11 is similar to Fig. 10 but for the Northern Hemisphere in ASO. For the eastern North Pacific, wind shear is the main contributor to the ENSO genesis potential anomalies, with potential intensity also playing a role, and vorticity and relative humidity acting in the opposite sense to the total observed anomaly. In the Atlantic, relative humidity (unfortunately, the variable in which we have the least confidence in the reanalysis) has the strongest contribution, with wind shear also playing a significant role, and potential intensity and vorticity playing weaker, if not necessarily negligible, roles. In the case of the western North Pacific, the negative anomaly near the Asian continent is mainly owing to relative humidity, with an additional contribution from the potential intensity. The increase near the date line is mainly due to vorticity, as claimed previously by Wang and Chan (2002) and Chu (2002), with additional contributions from wind shear and relative humidity.

It is interesting to note that the PI anomalies are negative in the western part of the western North $\mathrm{Pa}$ cific in El Niño years, despite the occurrence of more intense typhoons in El Niño years. This is in agreement with the lack of a relationship between local SST in the western North Pacific and tropical cyclone activity in that region (Chan and Liu 2004; Chan 2005, 2006). It also supports the notion that the increase in intensity in the western North Pacific (WNP) during El Niño years is due to the longer lifetimes that occur as a result of the eastward displacement in mean genesis location-that is, over these longer lifetimes, tropical cyclones are able to come closer to their potential intensities. The same explanation was given by Emanuel (2000) for the overall greater intensities of WNP storms compared to Atlantic storms.

In the Indian Ocean, there is a shift of the genesis potential from the northern to the southern part of the Bay of Bengal, mainly owing to wind shear, which is also mainly responsible for the anomalous positive genesis potential in the Arabian Sea. Though the peak of the tropical cyclone activity in the eastern North Pacific 
(a)

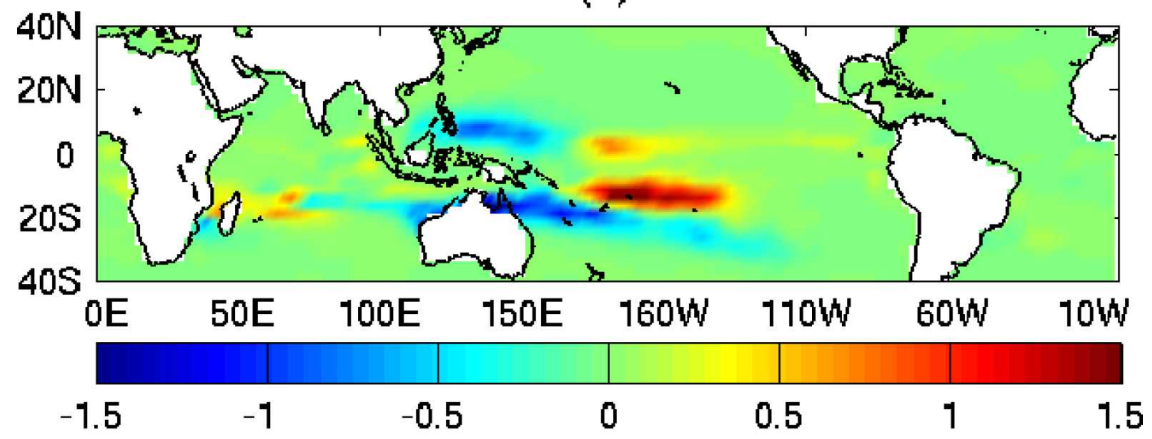

(b)

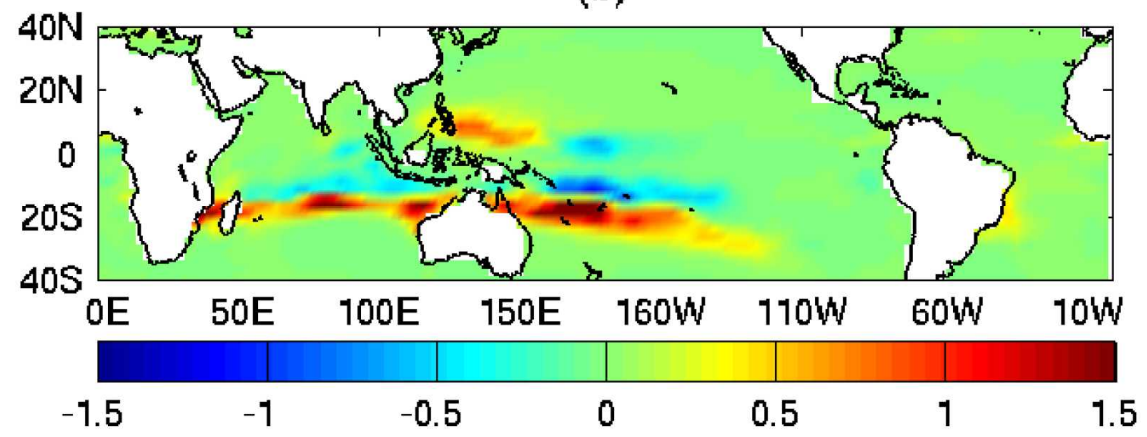

(c)

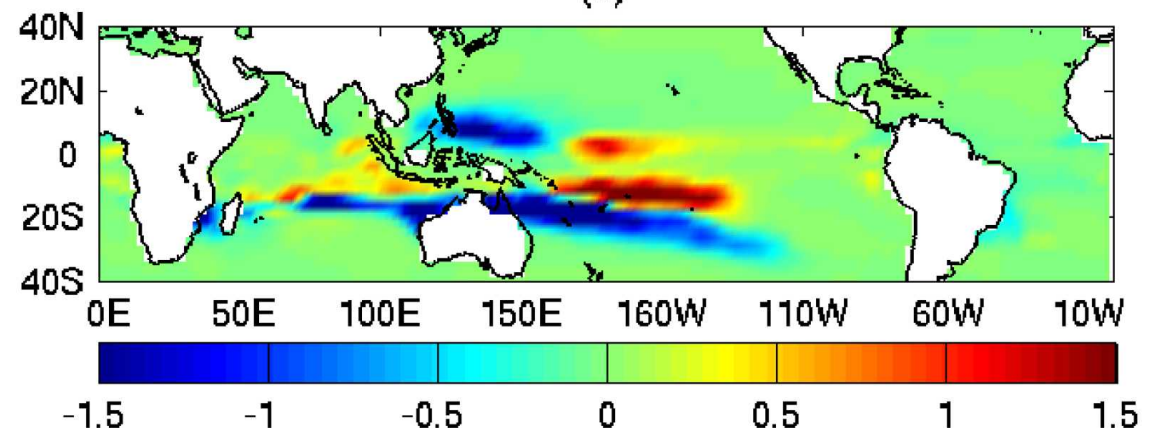

FIG. 8. Genesis potential anomalies in JFM for (a) El Niño and (b) La Niña years; (c) difference of the anomalies in El Niño and La Niña years.

and north Indian Ocean occurs in July-September (JAS) and October-December (OND), respectively (not shown here), the ASO figures are in agreement with those.

\section{Conclusions}

We have constructed annual cycle and ENSO composites of an empirical index of tropical cyclone genesis. The index was constructed from only the climatological annual cycle in each hemisphere as a whole, using no information from individual basins nor any interannual variability whatsoever. Our goals were to test the ability of the index to reproduce observed variations in tropical cyclone activity with the annual cycle and ENSO and then to use modified versions of the index to determine which individual physical factors are most important in causing these variations.

The primary findings are as follows:

1) The index tracks the observed climatological annual cycles of tropical cyclone number in each individual basin separately.

2) The index successfully reproduces the most wellknown ENSO signals in the best-observed basins, such as the suppression of genesis in the Atlantic and the eastward shift in mean genesis location in the western North Pacific during El Niño. 
(a)

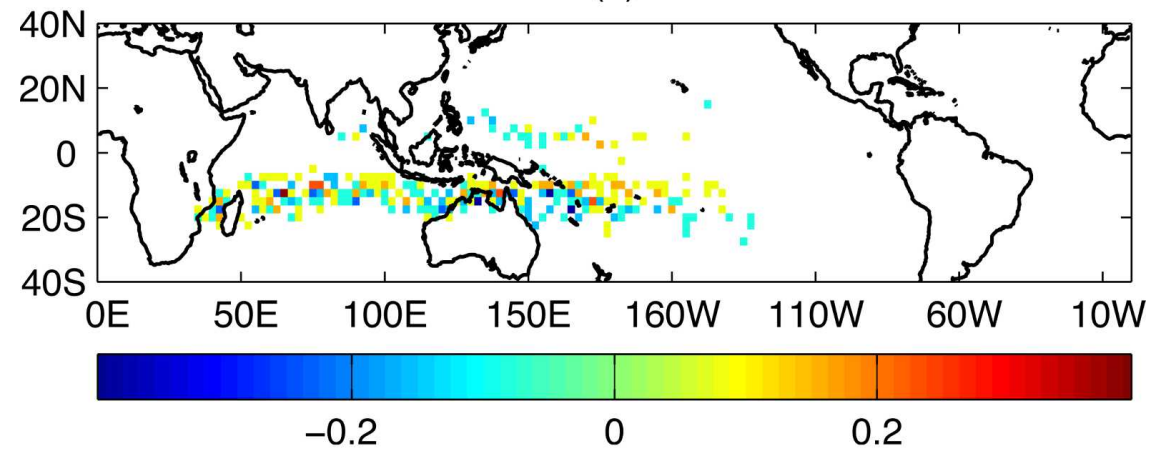

(b)

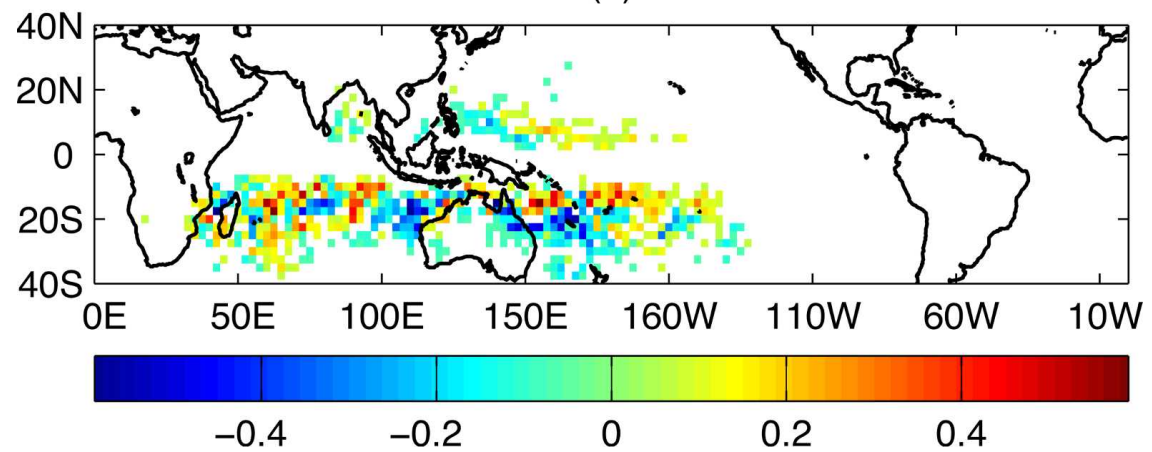

FIG. 9. Difference of the anomalies in El Niño and La Niña years for the (a) genesis density and (b) track density in JFM.

3) The different factors entering the index contribute differently to its ENSO anomalies in different regions. Vertical wind shear and midlevel relative humidity are consistently important in many basins, especially the western North Pacific near the Asian continent, the North Atlantic, and the Southern Hemisphere. Vorticity anomalies contribute most significantly in the central Pacific (both north and

TABLE 2. Correlations of the number of named tropical cyclones and the basin average genesis potential index in the period 1970-2005. The basins are defined by oceanic regions within the following ranges: in the Southern Hemisphere $\left(40^{\circ} \mathrm{S}-0^{\circ}\right)$, in the Northern Hemisphere $\left(0^{\circ}-40^{\circ} \mathrm{N}\right)$; longitudes: south Indian-SI $\left(30^{\circ}-100^{\circ} \mathrm{E}\right)$, Australian-AUS $\left(100^{\circ} \mathrm{E}-180^{\circ}\right)$, South Pacific - SP $\left(180^{\circ}-\right.$ $\left.110^{\circ} \mathrm{W}\right)$, north Indian-NI $\left(40^{\circ}-100^{\circ} \mathrm{E}\right)$, western North Pacific-WNP $\left(100^{\circ} \mathrm{E}-180^{\circ}\right)$, central North Pacific - CNP $\left(180^{\circ}-140^{\circ} \mathrm{W}\right)$, eastern North Pacific-ENP $\left(140^{\circ} \mathrm{W}\right.$ to American coast), Atlantic (American coast to African coast). Twelve 3-month continuous seasons were used from JFM to DJF. Only shown are seasons and basins in which tropical cyclones occurred in at least more than $50 \%$ of the years. Statistical significance was obtained using a two-tailed test, taking into account the autocorrelations of each time series following Livezey and Chen (1983). Bold face (underlined) indicates statistical significance at the $95 \%$ (90\%) level.

\begin{tabular}{|c|c|c|c|c|c|c|c|c|}
\hline \multirow[b]{2}{*}{ Season } & \multicolumn{8}{|c|}{ Region } \\
\hline & SI & AUS & SP & NI & WNP & $\mathrm{CNP}$ & ENP & ATL \\
\hline JFM & 0.23 & 0.25 & 0.18 & - & 0.27 & - & - & - \\
\hline FMA & 0.19 & 0.34 & 0.25 & - & 0.54 & - & - & - \\
\hline MAM & -0.15 & 0.35 & - & 0.18 & 0.65 & - & -0.05 & - \\
\hline AMJ & -0.14 & 0.16 & - & 0.28 & 0.50 & - & 0.07 & 0.11 \\
\hline MJJ & -0.24 & - & - & 0.37 & 0.46 & - & -0.10 & 0.29 \\
\hline JJA & - & - & - & 0.56 & 0.29 & - & 0.00 & 0.54 \\
\hline JAS & - & - & - & - & 0.10 & 0.45 & 0.26 & 0.63 \\
\hline ASO & 0.15 & - & - & 0.10 & 0.16 & 0.60 & 0.51 & 0.60 \\
\hline SON & 0.14 & -0.13 & - & 0.13 & 0.21 & $\overline{0.63}$ & $\overline{0.48}$ & 0.28 \\
\hline DND & 0.17 & 0.24 & - & 0.06 & 0.45 & - & $\overline{0.05}$ & 0.28 \\
\hline NDJ & 0.36 & 0.32 & 0.42 & 0.03 & 0.33 & - & - & - \\
\hline DJF & $\overline{0.42}$ & 0.29 & 0.38 & - & $\overline{0.44}$ & - & - & - \\
\hline
\end{tabular}


(a)

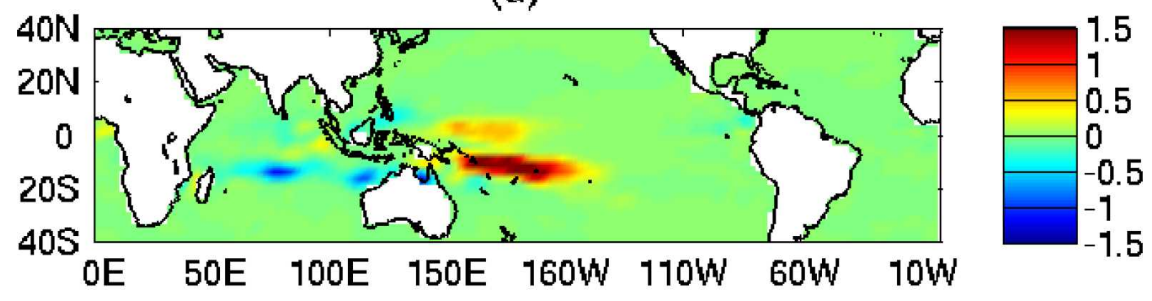

(b)

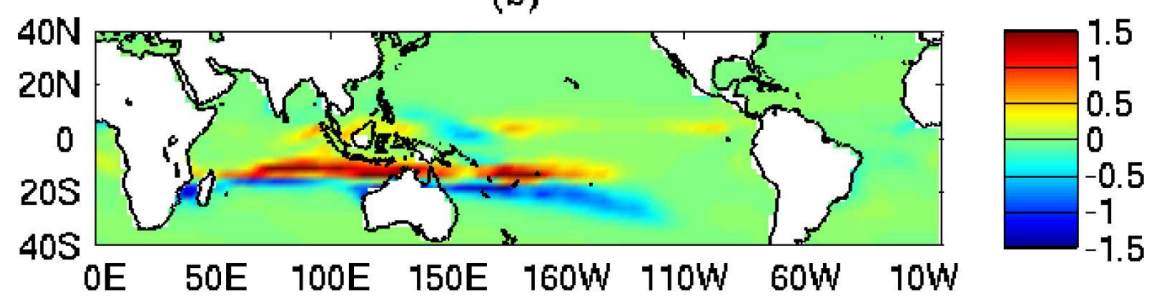

(c)

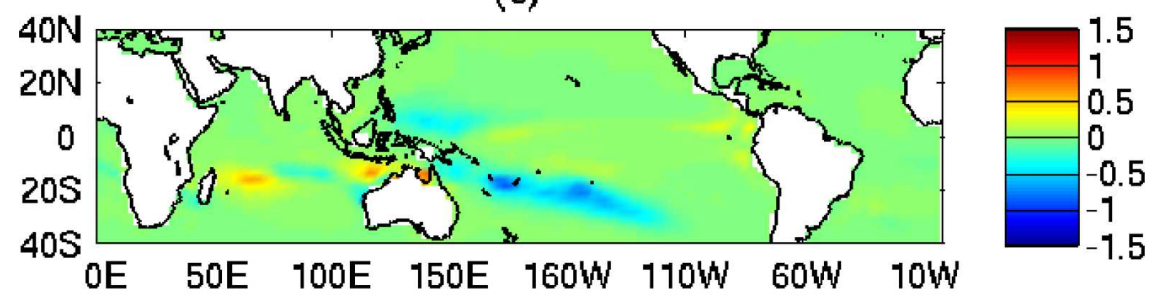

(d)

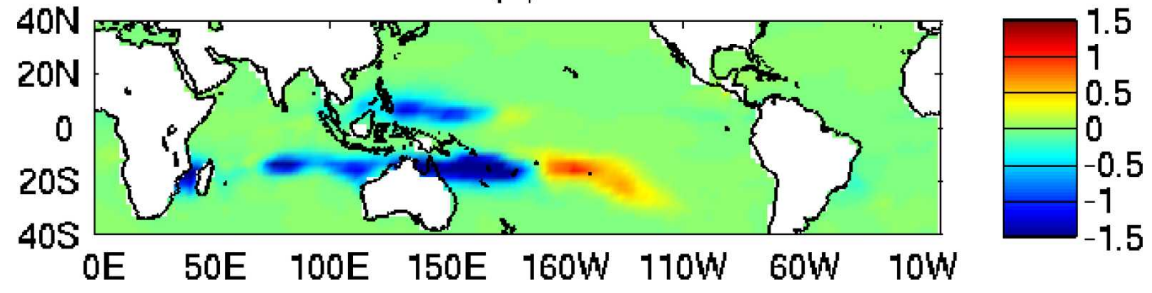

FIG. 10. Difference of El Niño and La Niña genesis potential composites in the Southern Hemisphere in JFM for varying (a) vorticity, (b) vertical wind shear, (c) potential intensity, and (d) relative humidity with the other variables as climatology.

south), where during El Niño events the tropical cyclones tend to form nearer the equator. Potential intensity plays a secondary role in the Atlantic, and varies oppositely to the observed variations in total genesis potential in the western North Pacific.

Acknowledgments. We thank Anthony G. Barnston for valuable discussions, and two anonymous reviewers who provided useful comments that led to improvements of the manuscript. This paper is funded in part by a grant/cooperative agreement from the National Oceanic and Atmospheric Administration (NOAA), Grant NA050AR4311004. The views expressed herein are those of the authors and do not necessarily reflect the views of NOAA or any of its subagencies. AHS acknowledges support from NSF Grant ATM-0542736 .

\section{APPENDIX}

\section{Potential Intensity}

The definition of potential intensity is based on that given by Emanuel (1995) as modified by Bister and Emanuel (1998). Details of the calculation may be found in Bister and Emanuel (2002a). The definition is also discussed online (http://wind.mit.edu/ emanuel/pcmin/ pclat/pclat.html). A FORTRAN subroutine to calculate the potential intensity is available online (http://wind.mit. edu/ emanuel/home.html). Monthly mean values may 
(a)

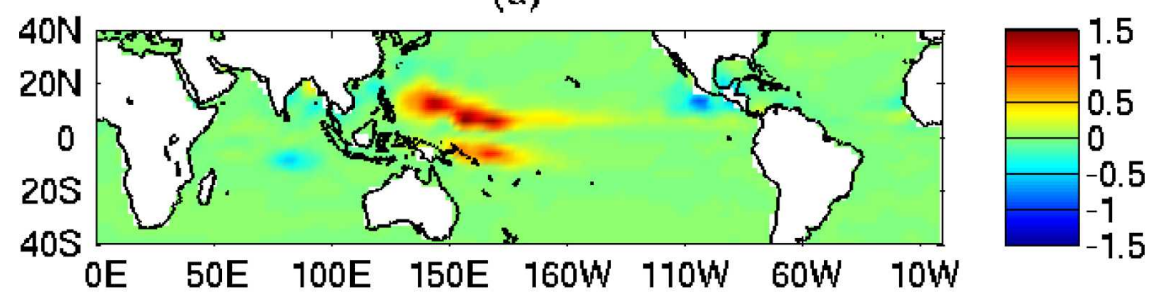

(b)
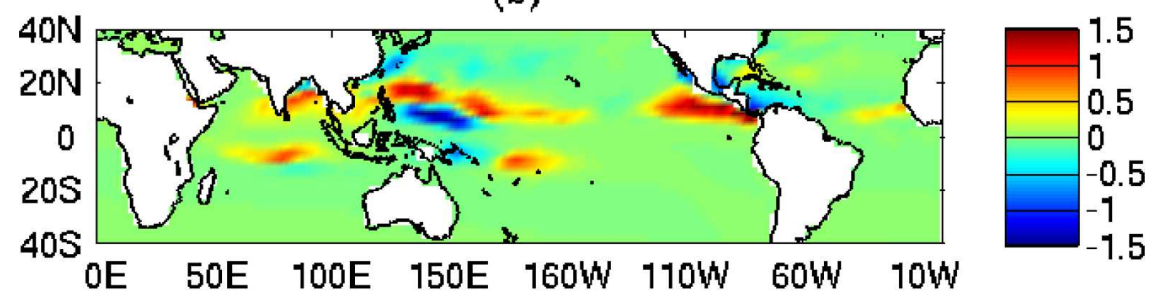

(c)

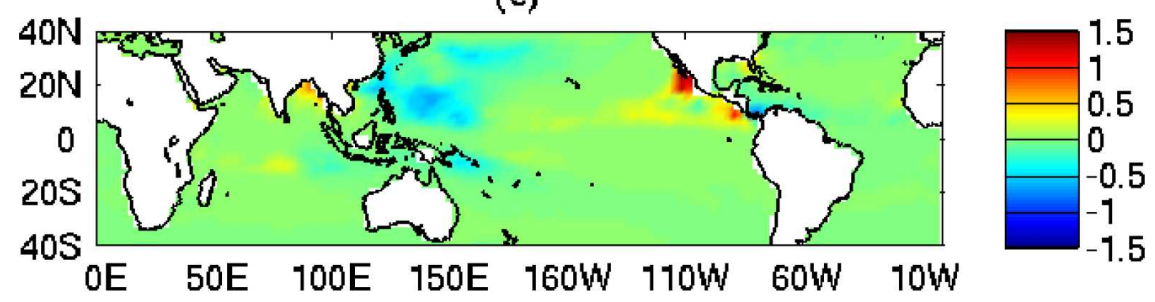

(d)

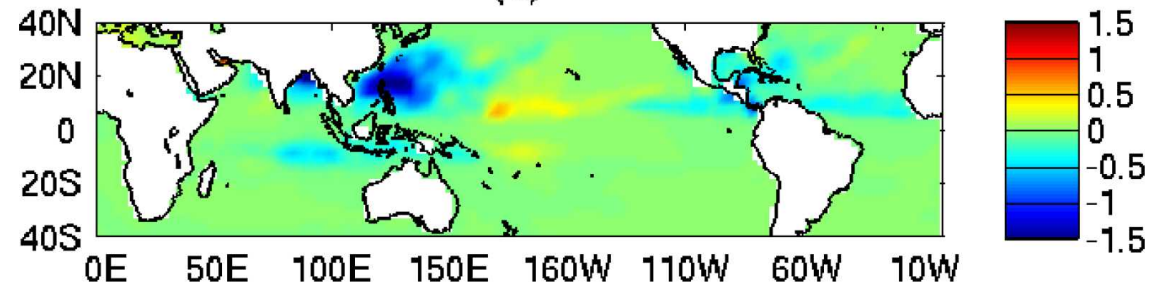

FIG. 11. Difference of El Niño and La Niña genesis potential composites in the Northern Hemisphere in ASO for varying (a) vorticity, (b) vertical wind shear, (c) potential intensity, and (d) relative humidity with the other variables as climatology.

be found at http://wind.mit.edu/ emanuel/pcmin/climo. html. Here we present a very brief overview of Bister and Emanuel (2002a). The formula they use is

$$
V_{\mathrm{pot}}^{2}=\frac{C_{k}}{C_{D}} \frac{T_{s}}{T_{0}}\left(\mathrm{CAPE}^{*}-\mathrm{CAPE}^{b}\right),
$$

where $C_{k}$ is the exchange coefficient for enthalpy, $C_{D}$ is the drag coefficient, $T_{s}$ is the sea surface temperature, and $T_{0}$ is the mean outflow temperature. The convective available potential energy (CAPE) is the vertical integral of parcel buoyancyI as a function of parcel temperature, pressure, and specific humidity, as well as the vertical profile of virtual temperature. The quantity $\mathrm{CAPE}^{*}$ is the value of CAPE for an air parcel at the radius of maximum winds, which has first been satu- rated at the sea surface temperature and pressure, while $\mathrm{CAPE}^{b}$ refers to the value of CAPE for ambient boundary layer air but with its pressure reduced (isothermally) to its value of at the radius of maximum wind. Thus, the variables used to calculate the potential intensity at each grid point are the sea surface temperature and pressure and vertical profiles of temperature and specific humidity.

\section{REFERENCES}

Basher, R. E., and X. Zeng, 1995: Tropical cyclones in the southwest Pacific: Spatial patterns and relationships to Southern Oscillation and sea surface temperature. J. Climate, 8, 12491260.

Bister, M., and K. A. Emanuel, 1998: Dissipative heating and hurricane intensity. Meteor. Atmos. Phys., 52, 233-240. 
, and —, 2002a: Low frequency variability of tropical cyclone potential intensity. 1 . Interannual to interdecadal variability. J. Geophys. Res., 107, 4801, doi:10.1029/2001JD000776.

$\longrightarrow$, and — 2002b: Low frequency variability of tropical cyclone potential intensity. 2. Climatology for 1982-1995. J. Geophys. Res., 107, 4621, doi:10.1029/2001JD000780.

Bove, M. C., J. B. Elsner, C. W. Landsea, X. Niu, and J. O'Brien, 1998: Effect of El Niño on U.S. landfalling hurricanes, revisited. Bull. Amer. Meteor. Soc., 79, 2477-2482.

Camargo, S. J., and A. H. Sobel, 2005: Western North Pacific tropical cyclone intensity and ENSO. J. Climate, 18, 29963006.

— A. W. Robertson, S. J. Gaffney, P. Smyth, and M. Ghil, 2007: Cluster analysis of typhoon tracks. Part II: Large-scale circulation and ENSO. J. Climate, 20, 3654-3676.

Chan, J. C. L., 1985: Tropical cyclone activity in the northwest Pacific in relation to the El Niño/Southern Oscillation phenomenon. Mon. Wea. Rev., 113, 599-606.

- 2005: Interannual and interdecadal variations of tropical cyclone activity over the western North Pacific. Meteor. Atmos. Phys., 89, 143-152.

— , 2006: Comment on "Changes in tropical cyclone number, duration, and intensity in a warming environment." Science, 311, 1713, doi:10.1126/science.1121522.

, and K. S. Liu, 2004: Global warming and western North Pacific typhoon activity from an observational perspective. $J$. Climate, 17, 4590-4602.

Chauvin, F., J.-F. Royer, and M. Déqué, 2006: Response of hurricane-type vortices to global warming as simulated by ARPEGE-Climat at high resolution. Climate Dyn., 27, 377399.

Chia, H. H., and C. F. Ropelewski, 2002: The interannual variability in the genesis location of tropical cyclones in the northwest Pacific. J. Climate, 15, 2934-2944.

Chu, P.-S., 2002: Large-scale circulation features associated with decadal variations of tropical cyclone activity over the central North Pacific. J. Climate, 15, 2678-2689.

- 2004: ENSO and tropical cyclone activity. Hurricanes and Typhoons, Past, Present and Future, R. J. Murnane and K.-B. Liu, Eds., Columbia University Press, 297-332.

—_, and J. Wang, 1997: Tropical cyclone occurrences in the vicinity of Hawaii: Are the differences between El Niño and non-El Niño years significant? J. Climate, 10, 2683-2689.

Clark, J. D., and P.-S. Chu, 2002: Interannual variation of tropical cyclone activity over the Central North Pacific. J. Meteor. Soc. Japan, 80, 403-418.

Collins, J. M., and I. M. Mason, 2000: Local environmental conditions related to seasonal tropical cyclone activity in the Northeast Pacific basin. Geophys. Res. Lett., 27, 3881-3884.

Dong, K., 1988: El Niño and tropical cyclone frequency in the Australian region and the North-western Pacific. Aust. Meteor. Mag., 36, 219-255.

Elsner, J. B., and A. B. Kara, 1999: Hurricanes of the North Atlantic: Climate and Society. Oxford University Press, 488 pp.

— esis. Climate Res., 25, 43-54.

Emanuel, K. A., 1988: The maximum intensity of hurricanes. $J$. Atmos. Sci., 45, 1143-1155.

_ 1995: Sensitivity of tropical cyclones to surface exchange coefficients and a revised steady-state model incorporating eye dynamics. J. Atmos. Sci., 52, 3969-3976.

— 2000: A statistical analysis of tropical cyclone intensity. Mon. Wea. Rev., 128, 1139-1152.
- and D. S. Nolan, 2004: Tropical cyclone activity and global climate. Preprints, 26th Conf. on Hurricanes and Tropical Meteorology, Miami, FL, Amer. Meteor. Soc., 240-241.

Evans, J. L., and R. J. Allan, 1992: El Niño/Southern Oscillation modification to the structure of the monsoon and tropical cyclone activity in the Australian region. Int. J. Climatol., 12, 611-623.

Ferreira, R. N., W. H. Schubert, and J. J. Hack, 1996: Dynamical aspects of twin tropical cyclones associated with the MaddenJulian oscillation. J. Atmos. Sci., 53, 929-945.

Goddard, L., and M. Dilley, 2005: El Niño: Catastrophe or opportunity? J. Climate, 18, 651-665.

Goldenberg, S. B., and L. J. Shapiro, 1996: Physical mechanisms for the association of El Niño and West African rainfall with Atlantic major hurricane activity. J. Climate, 9, 1169-1187.

Gray, W. M., 1979: Hurricanes: Their formation, structure and likely role in the tropical circulation. Meteorology over the Tropical Oceans, D. B. Shaw, Ed., Royal Meteorological Society, $155-218$

_ 1984: Atlantic seasonal hurricane frequency. Part I: El Niño and $30 \mathrm{mb}$ quasi-biennial oscillation influences. Mon. Wea. Rev., 112, 1649-1668.

_ and J. D. Sheaffer, 1991: El Niño and QBO influences on tropical cyclone activity. Teleconnections Linking Worldwide Anomalies, M. H. Glantz, R. W. Katz, and N. Nicholls, Eds., Cambridge University Press, 257-284.

_- C. W. Landsea, P. W. Mielke Jr., and K. J. Berry, 1993: Predicting Atlantic basin seasonal tropical cyclone activity by 1 August. Wea. Forecasting, 8, 73-86.

Hastings, P. A., 1990: Southern Oscillation influences on tropical cyclone activity in the Australian/South-west Pacific region. Int. J. Climatol., 10, 291-298.

Irwin, R. P., and R. Davis, 1999: The relationship between the Southern Oscillation Index and tropical cyclone tracks in the eastern North Pacific. Geophys. Res. Lett., 26, 2251-2254.

Kalnay, E., and Coauthors, 1996: The NCEP/NCAR 40-Year Reanalysis Project. Bull. Amer. Meteor. Soc., 77, 437-471.

Knaff, J. A., 1997: Implications of summertime sea level pressure anomalies in the tropical Atlantic region. J. Climate, 10, 789804.

Lander, M. A., 1994: An exploratory analysis of the relationship between tropical storm formation in the western North Pacific and ENSO. Mon. Wea. Rev., 122, 636-651.

_ 1996: Specific tropical cyclone track types and unusual tropical cyclone motions associated with a reverse-oriented monsoon trough in the western North Pacific. Wea. Forecasting, 11, $170-186$

Landsea, C. W., 2000: El Niño-Southern Oscillation and the seasonal predictability of tropical cyclones. El Niño: Impacts of Multiscale Variability on Natural Ecosystems and Society, H. F. Díaz and V. Markgraf, Eds., Cambridge University Press, 149-181.

_ R. A. Pielke Jr., A. M. Mestas-Nuñez, and J. A. Knaff, 1999: Atlantic basin hurricanes: Indices of climatic changes. Climatic Change, 42, 89-129.

Livezey, R. E., and W. Y. Chen, 1983: Statistical field significance and its determination by Monte Carlo techniques. Mon. Wea. Rev., 111, 46-59.

McDonald, R. E., D. G. Bleaken, D. R. Cresswell, V. D. Pope, and C. A. Senior, 2005: Tropical storms: Representation and diagnosis in climate models and the impacts of climate change. Climate Dyn., 25, 19-36.

Nicholls, N., 1979: A possible method for predicting seasonal 
tropical cyclone activity in the Australian region. Mon. Wea. Rev., 107, 1221-1224.

_- 1985: Predictability of interannual variations of Australian seasonal tropical cyclone activity. Mon. Wea. Rev., 113, 11441149.

- C. W. Landsea, and J. Gill, 1998: Recent trends in Australian region tropical cyclone activity. Meteor. Atmos. Phys., 65, 197-205.

Pan, Y. H., and A. H. Oort, 1983: Global climate variations connected with sea surface temperature anomalies in the eastern equatorial Pacific Ocean for the 1958-73 period. Mon. Wea. Rev., 111, 1244-1258.

Pielke, R. A., Jr., and C. W. Landsea, 1999: La Niña, El Niño and Atlantic hurricane damages in the United States. Bull. Amer. Meteor. Soc., 80, 2027-2033.

Revell, C., and S. Goulter, 1986: South Pacific tropical cyclones and the Southern Oscillation. Mon. Wea. Rev., 114, 11381144.

Royer, J.-F., F. Chauvin, B. Timbal, P. Araspin, and D. Grimal, 1998: A GCM study of the impact of greenhouse gas increase on the frequency of occurrence of tropical cyclone. Climatic Change, 38, 307-343.

Ryan, B. F., I. G. Watterson, and J. L. Evans, 1992: Tropical cyclone frequencies inferred from Gray's yearly genesis parameter: Validation of GCM tropical climates. Geophys. Res. Lett., 19, 1831-1834.

Saunders, M. A., R. E. Chandler, C. J. Merchant, and F. P. Roberts, 2000: Atlantic hurricanes and NW Pacific typhoons: ENSO spatial impacts on occurrence and landfall. Geophys. Res. Lett., 27, 1147-1150.
Shapiro, L. J., 1987: Month-to-month variability of the Atlantic tropical circulation and its relationship to tropical storm formation. Mon. Wea. Rev., 115, 2598-2614.

Singh, O. P., T. M. A. Khan, and M. S. Rahman, 2000: Changes in the frequency of tropical cyclones over the North Indian Ocean. Meteor. Atmos. Phys., 75, 11-20.

Sobel, A. H., and S. J. Camargo, 2005: Influence of western North Pacific tropical cyclones on their large-scale environment. $J$. Atmos. Sci., 62, 3396-3407.

Tang, B. H., and J. D. Neelin, 2004: ENSO influence on Atlantic hurricanes via tropospheric warming. Geophys. Res. Lett., 31, L24204, doi:10.1029/2004GL021072.

Wang, B., and J. C. L. Chan, 2002: How strong ENSO events affect tropical storm activity over the western North Pacific. J. Climate, 15, 1643-1658.

Watterson, I. G., J. L. Evans, and B. F. Ryan, 1995: Seasonal and interannual variability of tropical cyclogenesis: Diagnostics from large-scale fields. J. Climate, 8, 3052-3066.

Whitney, L. D., and J. Hobgood, 1997: The relationship between sea surface temperatures and maximum intensities of tropical cyclones in the eastern North Pacific Ocean. J. Climate, 10, 2921-2930.

Wu, G., and N.-C. Lau, 1992: A GCM simulation of the relationship between tropical-storm formation and ENSO. Mon Wea. Rev., 120, 958-977.

Wu, M. C., W. L. Chang, and W. M. Leung, 2004: Impacts of El Niño-Southern Oscillation events on tropical cyclone landfalling activity in the western North Pacific. J. Climate, 17, 1419-1428. 